\title{
O CONSENSO DE WASHINGTON E A PRIVATIZAÇÃO NA EDUCAÇÃO BRASILEIRA
}

\author{
THE WASHINGTON CONSENSUS AND THE \\ PRIVATIZATION IN THE BRAZILIAN EDUCATION \\ LE CONSENSUS DE WASHINGTON ET LA \\ PRIVATISATION DE L'ÉDUCATION BRÉSILIENNE \\ EL CONSENSO DE WASHINGTON Y LA PRIVATIZACIÓN \\ EN LA EDUCACIÓN BRASILEÑA
}

Maria Abádia da Silva *

\section{RESUMO}

A presente reflexão busca contribuir para a compreensäo dos processos que caracterizam a intervenção das instituiçôes financeiras nas politicas nacionais, implementados após o Consenso de Washington e feitos com o consentimento do governo federal. Revela, ainda, as forças econômicas e politicas interessadas na privatização da educação brasileira e os mecanismos introduzidos no âmbito da organização institucional, tornando-a atividade empresarial.

Palavras-chave: Políticas educacionais. Banco Mundial. Educação pública. Legislação educacional. Formação de professores. Bird.

* Doutora em Educação pela Universidade Estadual de Campinas (Unicamp, 1999). Professora do Departamento de Teoria e Fundamentos e do Programa de Pós-Graduação da Faculdade de Educação da Universidade de Brasília (abadia@unb.br). 


\section{INTRODUÇÃO}

No final dos anos oitenta, as políticas neoliberais foram apresentadas como única alternativa aos países em desenvolvimento, a fim de que pudessem inserir-se na modernidade, mas isso não ocorreu. Ao contrário, os governos nacionais foram submetidos a exigências políticas e econômicas que os tornariam ainda mais frágeis, dependentes e vulneráveis às decisões internacionais. As políticas definidas pelos organismos financeiros internacionais acabaram servindo não aos interesses dos que delas precisavam, mas aos dos homens de negócio (FRIGOTTO, 1999, p. 19) que as controlam e dos investidores e acionistas das empresas transnacionais que continuam mantendo seu locus de produção de conhecimento ancorado nos países capitalistas centrais.

A expansão do capital financeiro em busca de mercados levou os donos do capital a instalar-se por toda parte, e, nessa saga desconsideraram a história, a identidade, a cultura e as necessidades da população local, mas geraram outras demandas. Os homens de negócio exigiram dos países tomadores de empréstimos a aplicação de um programa de ajuste estrutural único e secundarizaram os diferentes graus de desenvolvimento, os estágios industriais, as características regionais da economia, os recursos ambientais, as necessidades sócio-educacionais e as diferenças culturais, geográficas, étnicas e religiosas.

Em novembro de 1989, os governos conservadores, diretores executivos e representantes das instituições financeiras internacionais, ministros da Fazenda, presidentes de bancos centrais e representantes dos governos das economias em desenvolvimento reuniram-se em Washington, a fim de procederem a uma avaliação da economia dos países tomadores de empréstimos, que apresentavam resultados insuficientes segundo lógica de acumulação de capitais. E, para fundamentar suas convicçōes, contaram com a publicação da obra Rumo à Retomada do Crescimento Econômico na América Latina (1986), de Bela Balassa, pelo Instituto de Economia Internacional, essencial na definição dos rumos da economia nos anos seguintes. Durante a reunião, os integrantes afirmaram a necessidade de reformas estruturais, de aplicação de um plano de estabilização econômica, e ratificaram a proposta neoliberal como condição para conceder novos empréstimos aos países periféricos. Para expressar as convicçôes desses senhores do capital, John Williamson elaborou o modelo de reforma a ser aplicado pelos governos nacionais, devedores aos organismos financeiros e credores internacionais. O documento conhecido como Consenso de Washington (KUCZYNSKI; WILLIAMSON, 2004, p. 285) efetivamente imprimiu o modelo neoliberal de desenvolvimento econômico a ser implementado pelos governos nacionais nas décadas seguintes.

Para os homens de negócio, o diagnóstico sobre a América Latina apontava a vulnerabilidade dos países às crises como um dos impedimentos ao crescimento econômico e que um conjunto de medidas, as reformas de primeira geração, estimulariam uma maior circulação de capitais na região, nos anos 90 . Então, quais são as reformas de primeira geração? A reforma do Estado, da previdência e reforma fiscal, a política de privatização de empresas estatais, a redução orçamentária de gastos públicos nacionais, o controle inflacionário, a política de facilitação de competitividade externa, a desregulamentação e regulamentação pela ótica privada, a estabilidade das instituições bancárias, a liberalização do fluxo de capitais, a obtenção de superávit primário, a política de incentivo do setor 
privado e de flexibilização dos contatos de trabalho (KUCZYNSKI; WILLIAMSON, 2004, p. 7 e 284).

A avaliação das reformas de primeira geração na América Latina, em especial da Argentina e Chile, é positiva, dizem os mentores da reforma. Os defensores dessas reformas reconhecem que as medidas foram insuficientes ou incompletas (STIGLITZ, 1998, p. 691 e RAMOS, 1997, p. 17). No Seminário Mudanças políticas e econômicas no Brasil e na América Latina: balanço e perspectivas (1990-2002), realizado na Universidade de Brasília nos dias 23 e 24 de julho de 2002, John Williamson enfatizou que o Brasil deve aprofundar as reformas, ao invés de abandoná-las, e caminhar no sentido da construção da segunda geração de reformas, consolidando-as.

De fato, na obra Depois do Consenso de Washington (2004, p. 236) as reformas de segunda geração englobam um aprofundamento da reforma do Estado, dos serviços ofertados pelas instituições públicas: escolas e universidades, e instituições do sistema de saúde. Dentre as reformas de segunda geração destacamos: a implementação dos acordos assinados com a Organização Mundial de Comércio - OMC, a adoção de códigos e normas financeiras internacionais, o combate à corrupção, a intensificação da flexibilidade dos contratos de trabalho, a construção de uma rede de segurança social e a redução da pobreza. A convicção dos gestores executivos é de aprofundamento das reformas, com a intenção de redesenhar as instituições nacionais, colocando-as a serviço do capital. Diz o documento: "não é mais se as instituições importam, mas quais instituições importam e como consegui-las" (KUCZYNSKI; WILLIAMSON, 2004, p. 236).

Um registro faz-se necessário: o governo federal, entre 1990 e 2002, tornou-se sujeito ímpar no processo de ajuste e implementação de políticas sociais de corte neoliberal, na medida em que alterou a Constituição Federal de 1988, por meio de emendas e leis infraconstitucionais, além de medidas provisórias (MP). Portanto, ao subscrever os acordos internacionais com FMI e Banco Mundial, exigiu que o governo, no plano interno, instituísse preceitos jurídicos e normativos que reconfigurassem a ordem econômica e social do país.

Com esse raciocínio, a presente reflexão almeja contribuir para a compreensão dos processos que caracterizam a intervenção das instituições financeiras nas políticas nacionais, em especial nas educacionais, feitas com o consentimento do governo federal e de parte dos estaduais e das elites dirigentes nacionais. Inicialmente, foi pensado como uma ferramenta didático-pedagógica para estudantes de licenciatura e professores das redes de ensino fundamental e médio, com a finalidade de estimular a reflexão e outros estudos; por isso, optamos por este formato.

\section{QUEM SÃO E O QUE FAZEM OS ORGANISMOS FINANCEIROS INTERNACIONAIS?}

1. Ao final da 2a Guerra Mundial (1944), na Conferência Monetária e Financeira das Nações Unidas, em Bretton Woods, New Hampshire, Estados Unidos da América, foram criadas duas instituições financeiras internacionais: o Banco Mundial e o Fundo Monetário Internacional. Juntas tornaram-se as guardiās dos interesses do capital e com capacidade para induzir políticas econômicas e o destino de continentes e países em todo 
o planeta. O Banco Mundial possui 181 países membros; destes, 174 recebem ordens de apenas sete - Alemanha, Canadá, Estados Unidos, França, Inglaterra, Itália e Japão. No que se refere à força política, os Estados Unidos possuem $17 \%$ dos votos, e o poder de veto, e, juntamente com os sete países mais ricos, perfazem um total de $45 \%$ de votos. Já o Fundo Monetário Internacional agrega 183 países membros dos quais 177 juntos representam pouca força política nas tomadas de decisões e agem subordinados ao grupo de países mais poderosos. Seus pareceres são decisivos para os credores e atuam como termômetro da economia e da política dos países.

2. Em 1947, instituiu-se o fórum de arbitragem, negociação, regulação e supervisão das relaçóes comerciais internacionais, portador do instrumento jurídico denominado Acordo Geral sobre as Tarifas Aduaneiras e o Comércio (GATT). Dada a complexidade de interesses em disputa, o GATT foi substituído pela Organização Mundial do Comércio - OMC -, criada em janeiro de 1995 para promover o comércio entre os países, arbitrar as disputas comerciais, definir e fiscalizar o cumprimento de acordos e de normas de comércio entre os países, estimular a liberalização progressiva dos serviços públicos, em especial da educação de nível superior, e tratá-la com as regras comerciais. Em 2002, possuía 142 países membros, com sede em Genebra, na Suíça, onde trabalham cerca de 500 pessoas. A maioria dos seus sócios, incluindo o Brasil, mantém delegaçōes em Genebra, e é a partir de suas representações que os países reclamam os seus direitos comerciais.

3. No caso da educação, a Organização Mundial do Comércio, em reuniōes sucessivas, Seattle (1999), Sidney (2000), Gênova (2001) e Doha (2001) vem propondo a inclusão da educação na lista de produtos comercializáveis e subordinados às leis e à normatização dessa instituição (FOLHA DE SÃO PAULO, 2003, p. C1). A proposta desses homens de negócio é tornar a educação um serviço comercial subordinado às leis do mercado internacional. As questôes da privatização não se limitam à redução da participação do Estado em suas funções clássicas, mas sim, na sua reconfiguração e fortalecimento em favor do capital e das elites dominantes dispostas a explorar comercialmente os serviços públicos. Esse posicionamento está expresso nas reformas de segunda geração definidas pelo Banco Mundial e membros do Instituto de Economia Internacional.

4. Essas instituiçōes financeiras internacionais desempenham funções centrais na promoção e estimulação das políticas de privatização tanto no campo econômico, quanto no campo social, com a anuência dos governos nacionais. No Brasil, a partir dos anos noventa, diante das pressōes externas e da possibilidade de lucros imediatos que seriam auferidos pela elite dominante nacional, o governo brasileiro aceitou as determinaçôes externas. A sua disposição em governar atendendo aos interesses dos banqueiros e dos credores pode ser constatada no processo de desmantelamento do Estado nacionaldesenvolvimentista no campo social e na aplicação de políticas regulatórias nas áreas estratégicas que favorecessem os bancos estrangeiros e as empresas transnacionais.

5. As pressões dos investidores, credores e acionistas dos bancos e das empresas transnacionais, a fiscalização e a arbitragem da Organização Mundial do Comércio e a intervenção do Fundo Monetário Internacional e do Banco Mundial constituem os elementos cruciais para se obter do governo federal, parte dos estaduais e elites dominantes, o consentimento, que se efetiva mediante subscrição ao modelo de desenvolvimento econômico neoliberal e na disposição do governo federal em praticar medidas restritivas 
no campo social e educacional. Os gestores executivos do Banco Mundial afirmaram as seguintes medidas, encaminhando-as aos governos nacionais que estavam com dificuldades econômicas de pagamento da dívida externa: ampliar a abertura comercial, aplicar o plano de estabilização monetária, controlar o déficit público, reduzir a presença do Estado na oferta dos serviços públicos, favorecer a liberdade para circulação de capitais externos, reformar o Estado, ampliar a liberdade para as atividades comerciais e de mercado, implementar políticas de privatização de empresas estatais, eliminar as barreiras impostas ao fluxo de capitais estrangeiros e estimular o desenvolvimento de empreendimentos privados nacionais e internacionais.

6. Ao contrário do pretendido durante o Consenso de Washington (1989) pelos seus integrantes, os governos dos países tomadores de empréstimos que aplicaram as medidas propostas estão mais endividados, suas economias desorganizadas, a moeda erodida e apresentam resultados financeiros e econômicos insatisfatórios acompanhados de graves desigualdades sociais e aumento da miséria e penúria. Basta observar o desajuste social e econômico a que foram submetidos vários países da América Latina, entre 1990 e 2002, o que, somado às históricas dificuldades econômicas, revela não só os equívocos da política econômica, mas também a continuidade dos baixos índices de desenvolvimento social, desemprego e empobrecimento generalizado.

\section{COMO OCORRE O CONSENTIMENTO DO GOVERNO FEDERAL E DE SEUSALIADOS?}

1. A partir dos anos 90, no Brasil, o governo federal, parte dos governos estaduais e municipais, além das elites empresariais dirigentes subscreveram e se dispuseram a implementar, gradualmente, as medidas econômicas de corte neoliberal. De fato, passaram a desmontar o Estado nacional-desenvolvimentista voltado para a construção da infraestrutura, pólos industriais e petroquímicos, indústria de base, rede de transportes e provedor dos direitos sociais, com o argumento de que a intervenção estatal coibia o desenvolvimento do capital. O governo federal e as elites dominantes, sob a influência dos homens de negócio e dos credores privados e acionistas de empresas transnacionais, passaram a defender um Estado que se ocupasse dos interesses do capital, com o livre mercado, e que tivesse firmeza na contenção dos investimentos públicos na área social, em especial na educação pública.

2. Essa decisão política vem induzindo a privatização das políticas sociais - saúde, educação, previdência social e segurança -, que não decorre apenas das decisões econômicas baseadas no uso racional dos investimentos públicos. É mais que isso. É uma decisão política de governo sustentado nas premissas neoliberais de que são atividades não exclusivas de Estado e que podem ser objeto de concessão à iniciativa privada. Somase a esse princípio outros como a necessidade de redefinição das funções do Estado e as pressōes de acionistas de empresas e de corporaçōes internacionais para a abertura de mercados para a expansão de seus negócios comerciais, no campo da educação.

3. A disposição do governo federal em estabelecer sintonia com as políticas pactuadas com o Banco Mundial no campo da educação pode ser encontrada no documento Planejamento Político-estratégico (maio de 1995), em que sinaliza a "progressiva transformação 
do Ministério da Educação num organismo eficaz de formulação, coordenação e acompanhamento de políticas públicas na área educacional e a conseqüente redução de seu papel executivo". É exemplar o artigo $8^{\circ}, \$ 1^{\circ}$, da Lei n. 9.394/1996: "Caberá à União a coordenação da política nacional de educação, articulando os diferentes níveis e sistema e exercendo função normativa, redistributiva e supletiva em relação às demais instâncias educacionais". Há uma mudança de concepção. Nos anos 80, o papel do Estado era o de executor da política nacional de educação, e nos anos 90 passa a ser o coordenador desta política, cumprindo papéis supletivo e distributivo. Esses são alguns dos mecanismos introduzidos na legislação educacional estruturantes da ordem privada neoliberal, e uma das estratégias do Estado é a de organizar a educação, disponibilizando-a, em segui$\mathrm{da}$, ao setor empresarial.

4. O Estado no Brasil tornou-se o promotor da privatização no campo social e educacional, enfraquecendo as instituiçōes sociais, e algumas vezes se sobrepondo ao Congresso Nacional. Ao mesmo tempo, aperfeiçoa novas formas de clientelismo, especialmente nas relações com as entidades privadas na esfera educacional: fundaçōes, institutos de ensino, empresários de equipamentos e informática, editoras, empreiteiras, empresas de propaganda oficial e empresas do setor de alimentação escolar. Portanto, a natureza do processo privatizador excludente não está fora do Estado, senão dentro de sua própria estrutura e nos acordos pactuados com as forças econômicas, políticopartidárias que o constituem historicamente.

5. A privatização da educação pode se expressar em duas dimensões: uma, a redução e realocação de recursos estatais para a educação básica e superior, e a outra, a destinação de recursos públicos para o setor privado, seja pela concessão de benefícios tributários, seja pela isenção de impostos. É exemplar a atitude do governo federal ao anunciar um aumento de \$250 milhôes de reais nas verbas para financiar a expansão e a melhoria do ensino privado (FOLHA DE SÃO PAULO, 23/02/2000), e a nítida relutância em aumentar o valor mínimo por aluno previsto no Fundo de Manutenção e Desenvolvimento do Ensino Fundamental e de Valorização do Magistério - Fundef. Outro exemplo foi a atitude de Fernando Henrique Cardoso, ao vetar nove artigos do Plano Nacional de Educação - Lei n. 10.172/2001, que versavam sobre elevação dos percentuais para a educação pública. No entanto, há uma disposição do governo federal em reduzir os recursos públicos para a educação. Numa estratégia de aparente normalidade e utilizando-se da mídia, quer fazer o deslocamento das instituições públicas, historicamente na esfera pública, para a esfera de direito privado, consubstanciado nas chamadas organizaçôes sociais (CHAUÍ, 1999, p. 51).

6. Os desdobramentos desse modelo de desenvolvimento econômico e social tornam-se presentes nas políticas assistencialistas e compensatórias destinadas ora à manutenção do status quo, ora ao alívio parcial da pobreza. Essas políticas são focalizadas, insuficientes e pouco articuladas, não modificam a realidade, mas provocam a seguinte reflexão: como o governo federal pensa o dilema: subscrever as políticas de $2^{a}$ geração dos organismos financeiros e ao mesmo tempo cumprir as metas e os compromissos internos? Como não subordinar as políticas sociais às políticas econômicas? De que setores o governo federal vai reduzir verbas para depois remetê-las aos credores internacionais? Por que os governos federal e estaduais solicitam empréstimos ao Banco 
Mundial para projetos na educação pública e, depois, os mesmos técnicos e consultores do banco e do governo federal, via ministérios da Fazenda, do Orçamento e Planejamento pressionam, contingenciam e reduzem as verbas para a educação básica e para as universidades públicas?

7. A educação do país não pode ficar na dependência de recursos provenientes da assinatura de acordos e projetos externos. Esses são temporários, estão mergulhados nos trâmites da burocracia, sujeitos aos jogos de interesses econômicos, políticos e dos acionistas das empresas de educação. Uma política nacional de educação demanda ações consistentes, coesas e contínuas e a integração com as demais políticas sociais. Exige dos governos firmeza e prudência ao definir a dotação orçamentária e zelo durante sua implementação, fiscalização e reavaliação. Exige que a sociedade civil participe e decida, e que tenha acesso aos mecanismos de controle sobre as ações do próprio Estado.

8. De fato, se analisamos a memória histórica deste país, é possível constatar que o governo federal e seus aliados prescindiram da educação como elemento formador e emancipador dos seres humanos. Buscaram sim, no autoritarismo, assistencialismo, clientelismo e populismo maneiras para perpetuarem-se nas estruturas do Estado, beneficiando-se dele. A freqüência de decisões que contemplem os interesses privados revela uma das dimensões que o processo privatizador assume no campo sócio-educacional. Cabe ressaltar a atitude o governo federal, que, sob a égide dessas políticas privatistas, estimula uma série de açôes delegatórias à sociedade civil. $\mathrm{O}$ programa Adote uma Escola, o projeto Amigos da Escola, o Dia da Família na Escola, as atividades de trabalho voluntário na escola, a filantropia religiosa são destinados a substituir ou a complementarem responsabilidades do Estado, num país marcado por processos de exclusão social e desigualdades profundas.

9. A privatização dos serviços públicos tende a aprofundar as condições históricas de discriminação e de negação dos direitos e bens sociais e culturais a que está submetida ampla parcela da população brasileira. Cria-se, assim, um subsistema particular profundamente heterogêneo quanto às condiçõos de oferta e de qualidade na educação. Essas políticas geram um valor mínimo por aluno para as escolas privadas, e outro para as escolas públicas estaduais e municipais. Legitima-se, assim, um tratamento desigual e de qualidade diferenciada em todos os níveis escolares, agravando, ainda mais, as históricas ações de negação do direito à educação, do direito de aprender e de apropriar-se dos bens culturais. Faz-se necessário relembrar que os governos e as elites nacionais dominantes fizeram a nação brasileira prescindindo da escolarização de sua gente.

10. A perversidade da política de privatização no campo dos trabalhadores da educação pública vem se efetivando pela ausência de concursos públicos para a contratação de servidores técnico-administrativos e docentes. As medidas vigentes nas universidades públicas, e em parte da rede pública de ensino, coibiram a contratação de docentes ou prevêem a contratação temporária. Quanto aos docentes, estes são empurrados para captarem recursos com convênios e fundaçōes privadas. Quanto aos servidores técnicos administrativos, constata-se a existência de dois grupos. Num deles, remanescentes de concursos públicos completam suas rendas com recursos das fundaçôes. O outro grupo é formado por funcionários contratados sob a égide dos processos de terceirização, também explorados e submetidos a salários reduzidos e às restriçôes de direitos trabalhistas. 


\section{CONSIDERAÇÕES FINAIS}

Neste sentido, é preciso afirmar os desafios que estão colocados para os educadores: primeiro, a educação é um direito universal e dever inalienável do Estado; segundo, os valores humanos são essenciais à convivência social e não podem ser substituídos por valores comerciais e de mercado; terceiro, os investimentos públicos para a ciência, cultura e tecnologia são vitais para trilhar os caminhos de emancipação e soberania, a fim de que possamos posicionarmo-nos com autoridade de interlocução diante de outros países; quarto, na sociedade capitalista de classe, com tantas desigualdades sociais, regionais e locais, a organização da sociedade civil é vital. Portanto, a luta dos movimentos sociais, populares e sindicais fortalecida e redefinida pelos trabalhadores e em defesa dos seus direitos, tem longas batalhas pela frente.

Em uma outra direção, é preciso desprivatizar o Estado brasileiro. É preciso disponibilizar à população os instrumentos de controle social sobre as açōes do Estado. Um dos papéis do Estado é intervir para amenizar tantas desigualdades e zelar pelo bem comum público. Sua necessidade está não em servir aos homens de negócios, mas em servir aos homens e mulheres comuns nesta sociedade de classe e pluri-étnica. E, finalmente, a reconfiguração do Estado não pode significar a exclusão de direitos nem o comprometimento da democracia.

\section{Referências}

AVANCINI, Marta; SILVEIRA, Wilson. Particulares dominam ensino superior. Folha de São Paulo, 26/06/1999.

BALASSA, Bela. Toward renewed economic growth in Latin America. Washington: Institute for International Economics, 1986.

BRASIL. Congresso. Lei de Diretrizes e Bases da Educação Nacional. Lei n. 9.394/1996. Brasília: Congresso Nacional, 1996.

. MEC. Planejamento político-estratégico: 1995-1998. Brasília: Ministério da Educação e do Desporto, maio 1995.

CHAUÍ, Marilena. Ideologia neoliberal e universidade. In: OLIVEIRA, Francisco de; PAOLI, Maria Célia (Orgs.). Os sentidos da democracia. Rio de Janeiro: Fapesp/Vozes, 1999. p. 27-51.

CORREIO DA UNESCO. O ensino será uma mercadoria? Correio da Unesco, abr. 2000.

FOLHA DE SÃO PAULO. FMI sugere fim da universidade gratuita. Folha de São Paulo, $02 / 02 / 2001$.

. OMC discute novas regras para a educação. Folha de São Paulo, 30/03/ 2003. p. C1. Folha Cotidiano.

. Universidade privada ganha mais verba. Folha de São Paulo, 23/02/2000.

FRIGOTTO, Gaudêncio. Educação e capitalismo real. São Paulo: Cortez, 1999.

GENTILI, Pablo. Privatização da política educacional. Boletim Políticas Públicas. LPP - UERJ, n. 1, dez. 2000.

MONLEVADE, João Antonio; SILVA, Maria Abadia. Quem manda na educação no Brasil? Brasília: Idea. 2001. 
RAMOS, Joseph. Un balance de las reformas estructurales neoliberales en América Latina. Revista de la Cepal, n. 62, p., ago. 1997.

ROSENBURG Cynthia. O meganegócio da educação. Revista Exame, n. 7, p. 35-45, abr. 2002. SILVA, Maria Abadia da. Intervenção e consentimento: a política educacional do Banco Mundial. São Paulo: Fapesp e Autores Associados, 2002.

SOUZA, Hebert. Quem governa o Brasil? Folha de São Paulo, 11/08/1999.

STIGLITZ, Joseph. Mas instrumentos y metas ma amplias para el desarrollo. Hacia el consenso post-Washington. Desarrollo Econômico, v. 38, n. 151, p., 1998.

VEIGA, Ilma Passos; AMARAL, Ana Lúcia (Orgs.). Formação de professores: políticas e debates. Campinas: Papirus, 2002.

WILLIAMSON, John. Reformas políticas na América Latina na década de 80. Revista de Economia Política, São Paulo, v. 12, n. 45, p., jan.-mar. 1992.

WILlIAMSON, John; KUCZYNSKI, Pedro-Pablo. Depois do Consenso de Washington. São Paulo: Saraiva, 2004. 


\section{The Washington Consensus and the privatization in the Brazilian education}

\section{Abstract}

The present study aims at contributing to the comprehension of the processes which characterize the intervention of financial institutions in the national policies implemented after the Consensus of Washington and agreed upon with the consent of the federal government. It further reveals the economic and political forces interested in the privatization of Brazilian education as well as the mechanisms introduced within the institutional organization, turning it into a commercial activity.

Keywords: Educational policies. World Bank. Public education. Educational legislation. Teacher training. Bird.

\section{Le Consensus de Washington et la privatisation de l'éducation brésilienne} Résumé

La réflexion actuelle cherche à contribuer à la compréhension des processus qui charactérisent l'intervention des institutions financières dans les politiques nationales implantées suite au Consensus de Washington et établies avec l'accord du gouvernement fédéral. Elle révèle en plus les forces économiques et politiques intéressées dans la privatisation de l'éducation brésilienne bien comme les mécanismes qui ont été introduits au sein de l'organisation institutionelle, faisant d'elle une activité d'entreprise.

Mots clefs : Politiques éducationnelles. Banque Mondiale. Éducation publique. Législation éducationnelle. Formation de maîtres. Bird.

\section{El Consenso de Washington y la privatización en la educación brasileña}

\section{Resumen}

La presente reflexión intenta contibuir para la comprensión de los procesos que caracterizan la intervención de las instituciones financieras en las politicas nacionales, implementados después del Consenso de Washington y realizados con el consenso del gobierno federal. Revela también las fuerzas económicas y políticas interesadas en la privatización de la educación brasileña y los mecanismos introducidos en el ámbito de la organización institucional, transformándola en actividad empresarial.

Palabras-clave: Políticas educacionales. Banco Mundial. Educación pública. Legislación educacional. Formación de profesores. Bird.

Recebida Ia versão em: 16.10.2003

Aceita $2^{\mathbf{a}}$ versão em: 13.03.2005 